\title{
Insulin Resistance and
}

\section{Oligodendrocyte/Microvascular} Endothelial Cell Dysfunction as Mediators of White Matter

\section{Degeneration in Alzheimer's Disease}

\author{
Suzanne M. de la Monte ${ }^{1,2}$ - Paula Grammas ${ }^{3}$ \\ ${ }^{1}$ Department of Pathology and Laboratory Medicine, Providence VA Medical Center, \\ Women and Infants Hospital of Rhode Island, and the Alpert Medical School of Brown \\ University, Providence, RI, USA; ${ }^{2}$ Departments of Neurology, Neurosurgery, and Medicine, \\ Rhode Island Hospital, Providence, RI, USA; ${ }^{3}$ Department of Neuroscience, University of \\ Rhode Island, Kingston, RI, USA
}

Author for correspondence: Suzanne M. de la Monte, Pierre Galletti Research Building, Rhode Island Hospital, 55 Claverick Street, Room 419, Providence, RI 02903, USA.

Email: Suzanne_DeLaMonte_MD@Brown.edu

Doi: http://dx.doi.org/10.15586/alzheimersdisease.2019.ch8

\begin{abstract}
In Alzheimer's disease (AD), white matter (WM) degeneration begins early, increases with disease progression, and contributes to cognitive impairment, yet the mechanisms are poorly understood. This article reviews the roles of myelin loss, oligodendrocyte dysfunction, and microvasculopathy in relation to AD WM degeneration. Myelin loss impairs axonal function and its breakdown promotes oxidative stress, inflammation, and lipid peroxidation, further compromising the structure and function of axons. Oligodendrocyte dysfunction impairs homeostatic mechanisms needed to maintain myelin. Microvascular disease with endothelial cell pathology leads to thrombin activation and pro-inflammatory cytokine release, oxidative stress, and increased vascular permeability. Progressive fibrotic
\end{abstract}

In: Alzheimer's Disease. Thomas Wisniewski (Editor), Codon Publications, Brisbane, Australia. ISBN: 978-0-646-80968-7; Doi: http://dx.doi.org/10.15586/alzheimersdisease.2019

Copyright: The Authors.

License: This open access article is licensed under Creative Commons Attribution 4.0 International (CC BY 4.0). https://creativecommons.org/licenses/by-nc/4.0/ 
replacement of smooth muscle cells reduces vaso-responsiveness to metabolic demands. Fibrotic thickening of vessel walls narrows the lumens, rendering them more susceptible to occlusion, endothelial cell injury, and thrombin activation. Since normal physiological functions of oligodendrocytes and microvascular endothelial cells rely on intact insulin/insulin-like growth factor (IGF) signaling through cell survival, metabolic and anti-inflammatory pathways, conceivably, WM degeneration in $\mathrm{AD}$ is mediated by insulin and IGF resistance with attendant pathogenic targeting of oligodendroglia and endothelial cells. The apolipoprotein E- $\varepsilon 4$ genotype may serve as a co-factor in AD-associated glial-vascular WM degeneration due to its role as a mediator of insulin resistance.

Keywords: Alzheimer's disease; Insulin resistance; oligodendrocytes; thrombin; white matter

\section{INTRODUCTION}

Alzheimer's disease (AD) is the 6th leading cause of death and the most prevalent aging-associated dementia, afflicting over 5 million people in the United States. Despite intense and comprehensive research efforts over the past 4-5 decades, we still lack effective disease-modifying therapies, and thus, the annual economic burden of over $\$ 170$ billion continues to grow (1). Perhaps one of the main obstacles to success has been the failure to appreciate the full spectrum of disease which extends well beyond cerebral accumulations of amyloid-beta $(A \beta)$ and neuronal structural pathologies caused by abnormally phosphorylated tau. AD is mechanistically linked to: (i) insulin resistance; (ii) neuroinflammation; (iii) white matter (WM) atrophy with myelin loss and axonal degeneration; (iv) vasculopathy; (v) leukoaraiosis; (vi) blood-brain barrier disruption; (vii) oxidative stress; (viii) mitochondrial dysfunction; (ix) loss of neuronal plasticity; and (x) synaptic disconnection. Furthermore, consideration should be given to the concept that different mediators of neurodegeneration may emerge at various time points and could be inter-dependent. These points are not addressed by the present-day diagnostic and therapeutic approaches.

In light of the varied and complex nature of AD-associated pathologies, it is not surprising that mono-therapeutic strategies have failed to remediate this disease. The development of a more rational and effective therapeutic design requires that we attain a greater understanding of how various pathogenic processes contribute to the onset and progression of $\mathrm{AD}$. Furthermore, additional information about systemic and central nervous system (CNS) forces that drive the cascade of neurodegeneration could lead to preventive strategies. For example, a better understanding of how co-factors such as vascular disease, head trauma, and lifestyle exposures modify risk and the phenotypic features of AD could ultimately help refine and personalize diagnostics and therapeutics. In this regard, the role of vascular disease in $\mathrm{AD}$ has been strongly suggested by the finding that at least $40 \%$ of people with clinically diagnosed AD have significant cerebrovascular disease yet neither disease process would be regarded as sufficient to cause dementia (2). Correspondingly, the relatively recent incident decline in AD severity in the United States has been attributed to improved vascular protective care (3). 
Now it is time for investigators to re-focus their efforts by capturing a better understanding of the protean pathogenic factors that drive progressive neurodegeneration. Evidence- and mechanism-based approaches are needed to develop multi-pronged therapeutics, utilizing strategies that already have been successful for cancers and other chronic diseases.

\section{AD-ASSOCIATED WM PATHOLOGY}

White matter degeneration is a major and consistent but vastly under-studied abnormality in AD (Figure 1). Its occurrence was initially characterized in 1986 by Brun and Englund $(4,5)$ and subsequently shown to be an early pre-clinical abnormality (6). WM atrophy in AD is most pronounced in the parietal and temporal lobes, followed by the frontal lobes, whereas the occipital lobes tend to be spared (6). Consequently, the severities of WM atrophy correspond with the distribution and degree of cerebral cortical pathology. WM degeneration in AD is associated with loss of myelin and myelinated axons, together with dysfunction or loss of oligodendrocytes, increased activation of astrocytes, that is gliosis, and microvascular disease (7-9). Leukoaraiosis, an extreme form of WM degeneration in which the loss of myelinated axons is extensive and associated with WM hyperintensities by magnetic resonance imaging (MRI) (7-9), is most prominently distributed in periventricular and central compared with subcortical WM $(5,6,10-15)$.

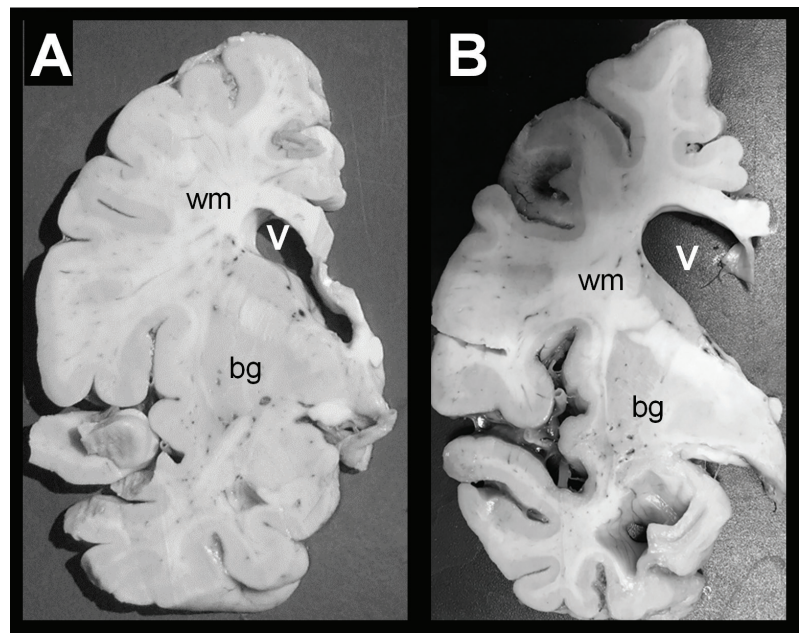

Figure 1 White matter atrophy in AD. Postmortem coronal slices of the left cerebral hemisphere from patients with (A) normal aging or (B) advanced AD. Panels A and B show approximately the same coronal slice levels depicting the cingulate gyrus, corpus callosum, basal ganglia (bg), central and periventricular posterior frontal white matter ( $\mathrm{wm}$ ) and lateral ventricle. Note the markedly atrophic white matter and associated ex vacuo enlargement of ventricles $(\mathrm{V})$ in $(\mathrm{B}) \mathrm{AD}$ relative to $(\mathrm{A})$ control. 
The histopathologic correlates of myelin degeneration in AD have been characterized by assessing relative reductions in Luxol fast blue (LFB) staining intensity and uniformity. LFB reacts with phospholipids and lipoproteins and is suitable for detecting myelin pathology in formalin-fixed, paraffin-embedded tissue. However, additional approaches are required to evaluate axonal degeneration and attrition. Traditional histochemical stains, such as Bielschowsky, utilize silver impregnation to label cytoskeletal proteins in axons, dendrites, and degenerated or dystrophic fibers. Current, more specific approaches employ immunohistochemical staining with antibodies to phosphorylated neuronal cytoskeletal proteins such as neurofilament and tau. In AD, myelin loss and axonal degeneration, respectively, marked by pallor of LFB staining and fragmentation, irregular swelling, and rarefaction of fibers, tend to be more pronounced in central and periventricular compared with subcortical WM, and they increase with severity of $\mathrm{AD}$.

\section{ASTROCYTES, MICROGLIA, AND OLIGODENDROCYTES}

Astrocyte activation or gliosis is a conspicuous feature of AD. Gliosis marks responses to cellular and tissue degeneration. One potential outcome of gliosis is tissue repair, but an alternative outcome is the elaboration of proinflammatory cytokines that promote oxidative stress and tissue injury, thereby worsening neurodegeneration. WM gliosis is marked by increased glial fibrillary acidic protein (GFAP) immunoreactivity in enlarged (hypertrophic) astrocytes and fibrillary deposits within the extracellular matrix (Figure 2). Dense fibrillary gliosis, which reflects severe degeneration, is most prominently distributed in periventricular and subcortical U-fiber regions. In contrast, central WM gliosis is generally less pronounced and associated with increased reactive hypertrophic astrocytes and variable densities of GFAP-positive fibrillary deposits.

WM gliosis, particularly in the early and intermediate stages of $\mathrm{AD}$, is accompanied by microglial activation. Microglia have rod-shaped, curved, or twisted nuclei and can be detected by immunohistochemical staining with antibodies to common leukocyte antigen (CD45) or ionized calcium-binding adaptor protein-1 (IBA-1) (16). In AD, activated microglia together with reactive astrocytes promote neuroinflammation via increased elaboration of pro-inflammatory cytokines and chemokines and suppression of anti-inflammatory molecules (17). Neuroinflammation causes injury and degeneration of myelin and axons. Although the underlying causes of WM neuroinflammation have yet to be determined, plausible etiologies include insulin/insulin-like growth factor (IGF) resistance and microvascular ischemic injury since both have been demonstrated in $\mathrm{AD}$ and are well-documented mediators of inflammation, oxidative stress, and metabolic dysfunction.

Oligodendrocytes synthesize and maintain myelin sheaths needed to support axonal integrity and function. Oligodendrocytes, like neurons, are highly vulnerable to both insulin and IGF-1 resistance and ischemic injury. Loss or dysfunction of oligodendrocytes impairs myelin maintenance, axonal function, and ultimately axonal structure. To better understand the mechanisms of WM degeneration 


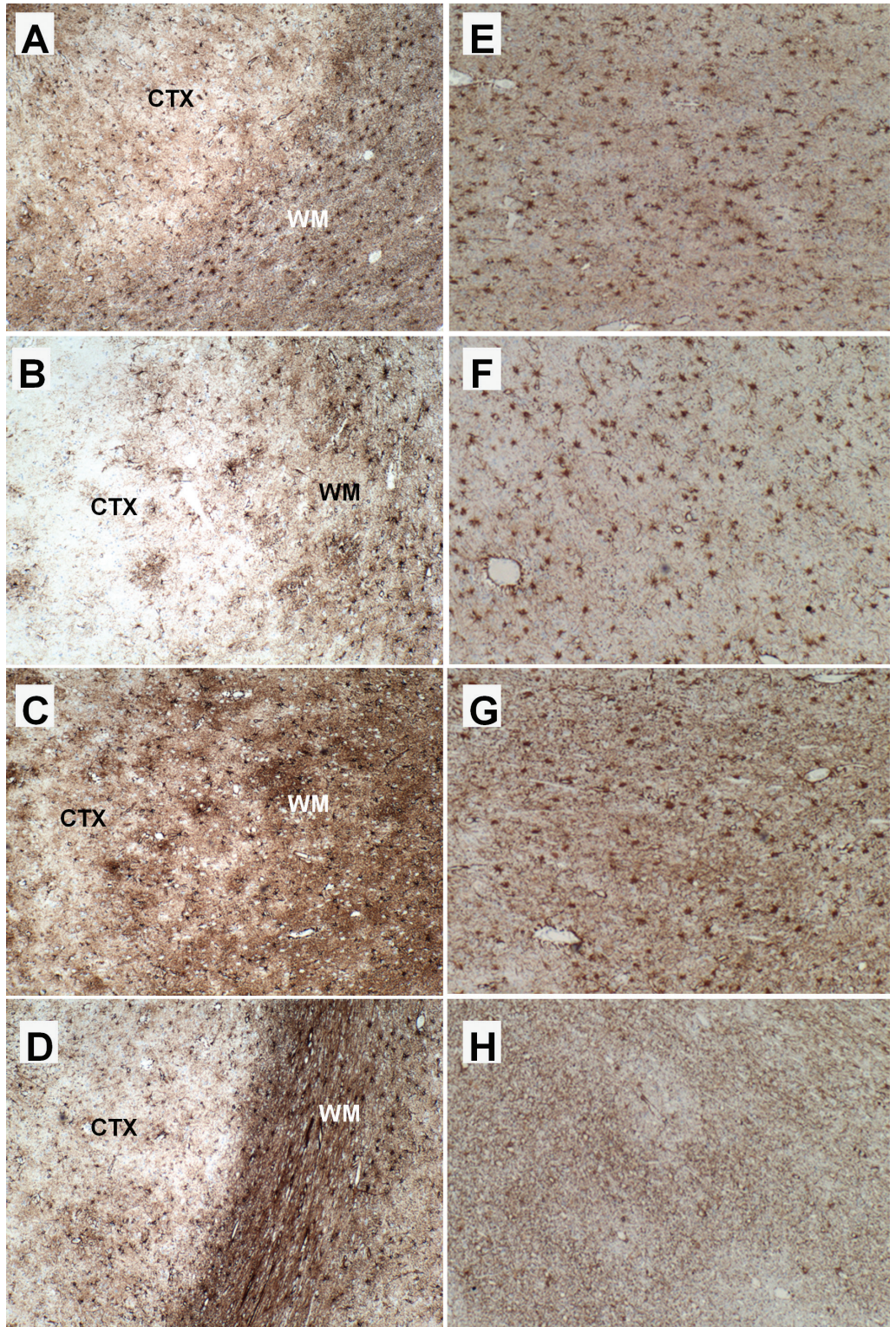

Figure $2 \mathrm{WM}$ gliosis exhibits regional variation in AD. Immunohistochemical staining was used to detect glial fibrillary acidic protein (GFAP) in the $(\mathrm{A}, \mathrm{E})$ anterior frontal, $(\mathrm{B}, \mathrm{F})$ posterior frontal, $(C, G)$ parietal, and (D, H) occipital cortex (CTX) and underlying white matter (WM) in formalin-fixed paraffin-embedded human postmortem brain tissue. Immunoreactivity was detected with biotinylated secondary antibodies, horseradish peroxidase-conjugated avidin-biotin complexes, and diaminobenzidine (brown precipitant). Panels A-D (100x original magnification) show intense GFAP immunoreactivity in white matter $(\mathrm{wm})$ and variable labeling of the cortex (ctx). Panels E-G (200x original magnification) show abundant GFAP-positive hypertrophic reactive astrocytes (dot-like structures) in a background of diffuse fibrillar labeling, whereas Panel $\mathrm{H}$ shows predominantly fibrillar labeling of central occipital WM. 
in $\mathrm{AD}$, more information is needed about the biochemical and molecular nature of oligodendrocyte injury and dysfunction leading to myelin and axonal loss. However, recent advances in adult brain WM cell isolation techniques (18), lipidomics mass spectrometry $(19,20)$, and targeted gene array analysis now provide practical methodologic approaches for characterizing WM oligodendrocyte and myelin lipid pathologies.

\section{BIOCHEMICAL AND CELLULAR BASIS OF WM PATHOLOGY IN AD}

White matter is largely composed of myelinated axons. Traditionally, the integrities of myelin and axons are studied by histochemical or immunohistochemical staining. However, overlapping responses to various types of injury and degeneration limit the utility of these approaches for characterizing disease-specific pathologies and responses to treatment. To better understand the nature of AD-associated myelin pathology, biochemical approaches that assess reproducible alterations in lipid composition are needed.

CNS myelin, a specialized membrane synthesized by oligodendrocytes, has a much higher dry mass of lipids (70-85\%) compared with proteins (15-30\%) and plays a major role in insulating axons to support conductivity. Myelin lipids primarily include cholesterol, glycosphingolipids, sulfatides, gangliosides, phospholipids, and sphingomyelin (21). Many diseases that impair the structural and functional integrity of WM are associated with abnormalities in the expression and metabolism of phospholipids and sulfatides (20, 22-28). Membrane phospholipids have important roles in regulating lipid rafts and receptor functions. Sulfatides, located on extracellular leaflets of plasma membranes (29) and generated via sulfonation of galactocerebroside, regulate neuronal plasticity, memory, myelin maintenance, protein trafficking, adhesion, glial-axonal signaling, insulin secretion, and oligodendrocyte survival (30). Degradation of sulfatide via galactosylceramidase and sulfatidase yields ceramide $(29,31)$, which promotes neuroinflammation, apoptosis, and production of reactive oxygen species (ROS), and impairs signaling through survival and metabolic pathways (32). Furthermore, deficiencies in membrane sulfatide disrupt myelin's structure, function, and capacity to support neuronal conductivity (32). Thus, imbalances in sphingolipid composition that reduce sulfatide and increase ceramide are potentially important mediators of WM degeneration and attendant cognitive impairment.

\section{Potential role of oligodendrocyte dysfunction as a mediator of WM degeneration}

Oligodendrocytes generate and maintain CNS myelin by controlling the expression and activity of enzymes that modulate its biosynthesis, turnover, and degradation (33-36). Loss or damage to myelin impairs neuronal conductivity and 
compromises axonal integrity, releasing neurofilament and myelin sulfatides (37). Increases in lipid peroxidation after myelin breakdown exacerbate oxidative damage, neuroinflammation, and astrocyte activation (gliosis). Therefore, the presence of WM atrophy and degeneration early in the course of $\mathrm{AD}$, including in its preclinical stages (6), could be due to pathogenic processes that impair function and survival of mature oligodendrocytes and promote secondary reactive injury via increased oxidative stress, inflammation, and lipid peroxidative. In light of the known importance of insulin and IGF signaling for maintaining a broad array of homeostatic functions in both neurons and oligodendrocytes (38-40), and strong evidence for brain insulin and IGF deficiencies and resistances beginning early in the course of $\mathrm{AD}(41,42)$, it is plausible to hypothesize that impaired signaling through the insulin and IGF receptors also mediates oligodendrocyte dysfunction in $\mathrm{AD}$.

Many critical functions of oligodendrocytes, including cell survival, myelin synthesis, and myelin maintenance, are supported by insulin and IGF-1 signaling (43-46). Consequently, disruption of related networks decreases oligodendrocyte viability, increases oxidative stress, and impairs myelin maintenance and maturation. Likewise, experimental models of chronically impaired brain insulin and IGF signaling exhibit WM atrophy and degeneration $(47,48)$ together with oligodendrocyte dysfunction (49), all of which can be partly reversed or prevented by early treatment with insulin sensitizers $(47,49)$. Another consequence of impaired insulin/IGF signaling is dysregulated sphingolipid metabolism resulting in decreased sulfatide and increased ceramide levels (23, 26-28, 50-52). Increases in ceramide can cause WM degeneration via several mechanisms, including inhibition of insulin/IGF signaling through pathways needed for oligodendrocyte survival and metabolic functions, and stimulation of pro-inflammatory and oxidative stress responses (28).

Besides lipids, oligodendrocytes synthesize integral membrane proteins whose expressions are differentially modulated at each stage of myelin maturation as well as in response to injury. As immature oligodendrocyte precursor cells (OPC) pass through phases of differentiation to eventually become mature myelin-producing oligodendrocytes, the proteins needed to support the structure and function of myelin also change. Mature oligodendrocytes express myelin basic protein (MBP), myelin-associated glycoprotein (MAG), myelin oligodendrocyte glycoprotein (MOG), proteolipid protein (PLP) (53), and adenoma polyposis coli (APC) (54), as well as O4 sulfatide (54). PLP is the most abundant protein in CNS myelin $(55,56)$. Olig 1-3 transcription factors are expressed at various stages of oligodendroglial maturation (54). Injury and degeneration of myelin cause the populations of intact mature functional oligodendrocytes to decline. That effect can lead to the proliferation of immature oligodendrocytes that express different myelin glycoproteins, transcription factors, and myelin glyco- and phospholipids which may not support optimum conductivity and CNS function. The conspicuous abnormalities in oligodendrocyte myelin-associated gene and lipid expression observed in human brains with AD and relevant experimental models including those linked to brain insulin and IGF resistance $(19,22-24,57)$, lend strong support the hypothesis that oligodendrocytes are targets of WM atrophy and neurodegeneration in $\mathrm{AD}$. 


\section{VASCULOPATHY, VASCULAR DEGENERATION, AND ISCHEMIC INJURY IN AD}

Small vessel disease is a recognized component of WM degeneration in AD, but its pathogenesis and contributions to neurodegeneration are poorly understood. The nature of vasculopathy and its progression to vascular degeneration and attendant ischemic injury require mechanistic understanding to guide preventive and therapeutic measures. Important initial steps include drawing distinctions between amyloid and non-amyloid associated vasculopathy and degeneration and characterizing the mediators and consequences of non-amyloid microvasculopathy, which is a feature of WM degeneration in AD.

The well-established AD-associated progressive declines in cerebral blood flow, glucose metabolism, and oxygen utilization suggest that impairments in brain perfusion are important components of $\operatorname{AD}(58,59)$. However, the extent to which vascular disease causes AD or represents an integral component of neurodegeneration remains controversial. Postmortem studies demonstrated cerebral vascular pathology in over $80 \%$ of brains with AD (60). In a separate postmortem study, substantial overlap was observed between AD and vascular-mediated injury, but very few cases of dementia could be attributed to vascular disease alone (2). The Gothenburg study reported that mental slowness and deficits in executive function were linked to WM vascular dysfunction and pathology but not cortical vasculopathy (37). Together, these studies suggest that although CNS vasculopathy contributes to AD, it is seldom sufficient to cause dementia on its own (37).

In $\mathrm{AD}$, there are two major types of microvascular pathology: amyloid angiopathy and non-amyloid vasculopathy (Figure 3). Amyloid angiopathy affects vessels in the cerebral cortex and leptomeninges, but not WM (61-63). In AD, non-amyloid vascular degeneration occurs in microvessels, including capillaries, arterioles, and venules in the cerebral cortex, WM, and subcortical nuclei. Nonamyloid microvascular disease is characterized by fibrotic thickening of vessel walls (sclerosis), loss of endothelial cells, thickening of basement membranes, attrition of perivascular tissue (64), reduced vascular density (micro-vasculopenia), and increased vessel coiling (65). Mural sclerosis leads to extreme narrowing of the lumens and reduced vaso-responsiveness, restricting perfusion, particularly in times of increased metabolic demand (66). Chronic hypoperfusion of WM causes ischemic injury ranging from myelin loss to fiber attrition, and in extreme cases, leukoaraiosis and micro-infarcts $(5,13)$. Another consequence of microvascular pathology is weakening and increased permeability of vessel walls as that occurs in diabetic nephropathy (67). Leakiness of microvessels enables toxins and inflammatory mediators from the peripheral circulation to enter the brain and cause perivascular tissue injury and attrition (58, 68-74).

\section{Potential role of nitric oxide in cerebral microvascular dysfunction and pathology}

Nitric oxide (NO) is an important physiological modulator of vascular smooth muscle function and blood flow. However, $\mathrm{NO}$ in high concentrations can be cytotoxic due to the activation of stress and inflammatory responses. 


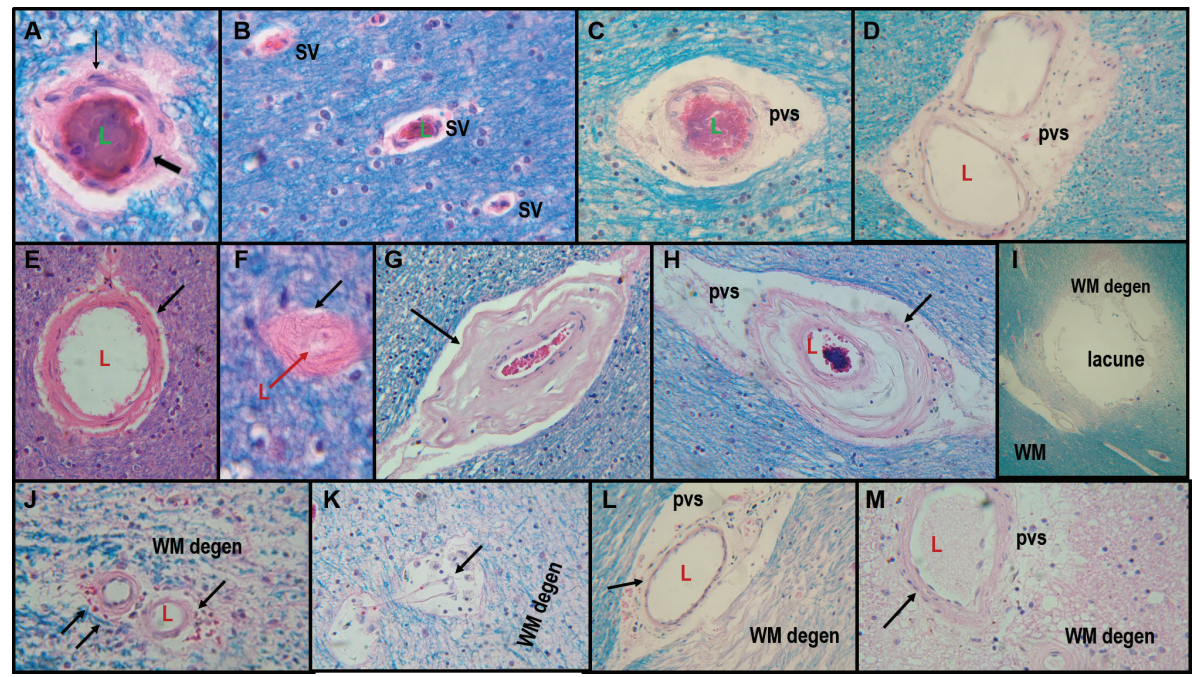

Figure 3 White matter (WM) vascular pathology in AD. Human postmortem parietal lobe samples were fixed in formalin, embedded in paraffin, and stained with Luxol fast blue (LFB), hematoxylin and eosin (LHE). (A, B) Control white matter (A) medium size and (B) small vessels (sv). Fine arrow in A shows normal smooth muscle cells and the broad arrow shows a normal endothelial cell. $\mathrm{L}=$ lumen. Panels $\mathrm{C}-\mathrm{M}$ depict vascular pathology in AD WM.

(C) Medium size vessel with reduced smooth muscle and a widened perivascular space (pvs) reflecting to perivascular tissue attrition. (D) Vascular fibrosis with enlarged pvs containing lipid-laden macrophages and hemosiderin deposits. (E) Vascular fibrosis (arrow) and myelin loss (markedly reduced LFB staining compared with A-D, and F-I). (F) Severe microvascular disease with fibrotic thickening (black arrow) and an extremely narrow lumen (red arrow; L). $(\mathrm{G}, \mathrm{H})$ Severe arteriosclerosis with degeneration and splitting of vessel walls, narrowing of lumens and in (H), widened pvs. (I) WM lacune (micro-infarct) associated with severe vascular degeneration and circumscribed area of WM degeneration. (J-M) Progressive WM degeneration associated with vasculopathy. WM degeneration is associated with loss of myelin staining, perivascular tissue attrition, and fiber loss. (M) Absent LFB staining and cystic degeneration of WM.

Microvascular degeneration is ultimately mediated by oxidative stress and inflammation. The potential role of $\mathrm{NO}$ as a mediator of vascular degeneration in $\mathrm{AD}$ was suggested by the findings that high levels of nitric oxide synthase (NOS) activity were co-localized with nuclear p53 in cerebral vessels (75) and cells with increased expression of pro-inflammatory and immune signaling genes (76). A later independent study of postmortem human brains demonstrated increased endothelial NOS (NOS3) immunoreactivity co-localized with nuclear p53 in AD microvascular smooth muscle and endothelial cells, confirming a role for aberrant NOS expression in cerebrovascular cells with increased proneness to apoptosis (77). Together, these findings suggest that non-amyloid vascular degeneration in $\mathrm{AD}$ is mediated by increased $\mathrm{NO}$ production and activation of inflammatory mechanisms.

However, the simultaneous detection of many sclerotic vessels with increased nuclear p53 but no detectable NOS3 immunoreactivity in either smooth muscle or endothelial cells, that is NOS3 expression was aberrantly down-regulated, suggests additional mechanisms mediate vascular dysfunction in AD (77). 
For example, degenerative vascular sclerosis compromises vaso-responsiveness and flow, resulting in chronic ischemic injury that can be exacerbated by repeated and multifocal thrombotic microvascular occlusions. Furthermore, fibrotic degeneration disrupts vessel wall integrity, rendering them more permeable to toxic-inflammatory factors from the peripheral circulation. This phenomenon could account for the perivascular tissue attrition that accompanies microvascular degeneration in AD (Figure 3).

\section{Thrombin activation, inflammation, microvascular occlusion, and ischemic injury in AD}

In $\mathrm{AD}$, the cerebral microcirculation is pathophysiologically activated due to endothelial cell overexpression of bioactive, neurotoxic, and inflammatory proteins including thrombin. Endothelial-derived thrombin is a multifunctional protease which in $\mathrm{AD}$, besides promoting vascular occlusion, functions as a stress-activated neurotoxin $(78,79)$. Mechanistically, thrombin initiates neuronal apoptosis via activation of glial and microglial cells, leading to increased oxidative stress and neuroinflammation (80). Thrombin also stimulates A $\beta$ precursor protein production and cleavage, mediates proteolytic processing of tau, and causes tau hyperphosphorylation and aggregation $(80,81)$. In essence, vessel-derived thrombin could represent a critical modulator of $\mathrm{AD}$ pathology via its regulation of inflammatory and bioactive protein expression. In this regard, thrombin activation of endothelial cells enhances expression and release of many pro-inflammatory proteins including monocyte chemoattractant protein-1 (MCP-1), intercellular adhesion molecule-1 (ICAM-1), IL-1, IL-6, and IL-8 (80, 81). Thus, microvascular disease could initiate and propagate neuroinflammation in AD.

Pro-inflammatory cytokine activation in endothelial cells leads to oxidative stress and thrombin release, with attendant thrombotic luminal occlusion or vessel wall injury causing increased permeability (82). However, the same responses can be mediated by up-regulation of the thrombin receptor protease-activated receptor 1 (PAR-1) or down-regulation of the brain thrombin inhibitor, protease nexin-1 near blood vessels (80). Since brain endothelial cells produce thrombin and also express functionally active PAR-1 and PAR-3 (79, 83), thrombin may initiate autocrine stimulation of a noxious feed-forward cycle. In addition, the intimate proximity of microvascular endothelial cells to microglia, astrocytes, and oligodendrocytes enables secretory products, including thrombin to influence cellular responses via a paracrine-type stimulation. For example, treatment of human

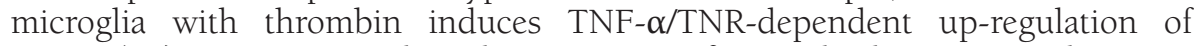
NF-kB (84). In astrocytes, thrombin activation of PAR-1 leads to increased MMP-9 expression through the regulation of several signaling pathways including PKC, JNK, and MAPK (85).

Microvascular endothelial cells elaborate trophic factors that positively impact oligodendroglia, but under conditions of stress, injury, or inflammation, endothelial cell dysfunction can adversely affect oligodendrocytes. An important role for endothelial-derived factors in oligodendroglial health was suggested by studies showing that endothelial cell-conditioned media enhances survival of OPCs (86, 87). On the other hand, in an experimental animal model of cerebral small vessel disease, early development of endothelial cell dysfunction was found to promote 
secretion of heat shock protein 90alpha and subsequently block oligodendroglial differentiation and production of mature myelin (88). Mechanistically, oxidative stress impairs the capacity of endothelial cells to generate trophic factors (89) needed to support critical functions of mature oligodendrocytes, including myelin maintenance.

In $\mathrm{AD}, \mathrm{WM}$ degeneration could stem from both endothelial and oligodendrocyte dysfunction. Endothelial cell dysfunction leading to excess thrombin release could cause micro-ischemic injury due to thrombosis or perivascular toxic injury mediated by increased vessel wall degeneration and permeability. At the same time, increased thrombin release would compromise the functional integrity of oligodendroglia, impairing survival and maintenance of mature myelin $(79,90-92)$. The concept that increased thrombin release could impair oligodendrocyte function is supported by the findings that the PARl thrombin receptor is a critical extracellular switch that controls myelination and that PAR1 deletion increases myelination (93), survival, maturation, and myelin maintenance. Altogether, the findings suggest that increased thrombin signaling by any one of several mechanisms can lead to micro-vessel-related WM injury in AD. However, the missing link is that we still do not understand the underlying causes of brain microvascular degeneration and endothelial cell dysfunction that lead to thrombin activation. One potential etiopathic candidate is insulin resistance since type 2 diabetes mellitus and other insulin resistance diseases are typically associated with microvascular disease and increased thrombin activation, accompanied by oxidative stress, platelet aggregation, vascular occlusions, and ischemic injury $(94,95)$. Correspondingly, insulin inhibits thrombin-induced endothelial dysfunction and mitigates microvascular permeability by decreasing thrombin-mediated vascular endothelial-cadherin translocation to the cytoskeleton/nuclear compartment (96).

\section{INSULIN AND INSULIN-IGF SIGNALING IMPAIRMENTS AS MEDIATORS OF WM GLIAL-VASCULAR DEGENERATION IN AD}

Considerable research had already demonstrated roles for impaired insulin and IGF-1 signaling in AD cortical and subcortical gray matter structures. However, little information is available regarding alterations of these same signaling pathways in AD WM degeneration, despite evidence that oligodendrocyte survival and function are dependent upon intact insulin and IGF networks. Therefore, additional research on the nature, mechanisms, and effects of impaired insulin and IGF signaling in relation to brain WM degeneration could generate a solid foundation for enhancing a broader understanding of the spectrum of brain pathology in $\mathrm{AD}$.

In $\mathrm{AD}$, deficits in brain energy metabolism, particularly concerning glucose utilization have been recognized for years (97-100). Positron emission tomography (PET) imaging with (18) F-fluoro-deoxyglucose (FDG) is a standard approach for detecting early impairments in brain glucose uptake and utilization (101-103). Insulin and IGF are major regulators of energy metabolism in the 
brain, and they have critical roles in maintaining broad neuronal and oligodendrocyte functions $(38,40)$. Impairments in brain insulin/IGF signaling due to insulin/IGF deficiencies or receptor resistances cause deficits in learning and memory (104).

Postmortem human studies demonstrated that AD is associated with significantly reduced expression of brain insulin and IGF polypeptides and receptors, insulin and IGF receptor tyrosine phosphorylation and receptor binding, activation of downstream pathways that promote cell survival, metabolism, neuronal plasticity, and myelin maintenance, and inhibition of signaling mechanisms that promote oxidative stress, neuroinflammation, cell death, and lipid peroxidation $(42,105,106)$. Insulin/IGF deficiencies and resistances increase with Braak stage severity of $\mathrm{AD}(41,105)$ and therefore correlate with accumulations of $A \beta$ and pTau pathologies. The finding that cerebrospinal fluid (CSF) insulin levels decline in the early or intermediate stages of $\mathrm{AD}$ (107), and overlap with progressive accumulations of $A \beta$ and advanced glycation end-products (AGEs) (Figure 4A) $(52,107,108)$ which cause oxidative stress and neuroinflammation, suggests that insulin deficiency contributes to progressive neurodegeneration in AD.

The human studies linking AD pathogenesis and progression to impairments in brain insulin/IGF signaling are supported by data from experimental models of sporadic AD produced by intracerebral (i.c.) administration of streptozotocin (STZ). STZ, a pro-diabetes toxin, injected into the cerebral hemispheres and ventricles, causes selective insulin deficiency and resistance in the brain with deficits in learning and memory, elevated levels of pTau, A $\beta$, and ubiquitin, loss of neurons, gliosis, oxidative stress, neuroinflammation, WM atrophy, and microvascular disease $(47-49,104,109)$. Importantly, data from these models support the concept that sustained and progressive deficits in brain insulin/IGF signaling cause nearly all of the known structural, functional, biochemical, molecular, and neurobehavioral abnormalities identified in AD. Correspondingly, insulin administration improves working memory and cognition (110-113) and enhances $A \beta$ clearance (114). Moreover, CNS-appropriate insulin sensitizer drugs have been shown to prevent or reduce AD-associated abnormalities in experimental animals $(49,109,115)$.

Until now, the adverse effects of brain insulin/IGF deficiencies and resistances have been focused on neurodegeneration and the functional impairments in gray matter structures due to the interest in linking them to standard neuropathological processes. Additional research is needed to determine how insulin/IGF-1 metabolic dysfunction mediates other aspects of AD. In this regard, recent preliminary studies showed that with the increasing severity of $\mathrm{AD}, \mathrm{WM}$ atrophy and degeneration are associated with corresponding impairments in the expression of Akt pathway proteins and phosphoproteins (de la Monte, S.M. and Tong, M, Unpublished). Compromised signaling along these pathways could lead to loss of structural and functional integrities of oligodendrocytes and myelin. Although the steps leading from brain insulin and IGF deficiencies and resistances to WM degeneration have not yet been delineated, clues may be harnessed from data generated via unrelated experiments. For example, several studies have shown that WM atrophy and degeneration in other models of brain insulin and IGF resistances were associated with significant oligodendrocyte dysfunction. For example, in a rat model of i.c. STZ, WM degeneration was associated with reduced expression of mature myelin-associated genes and increased expression of 

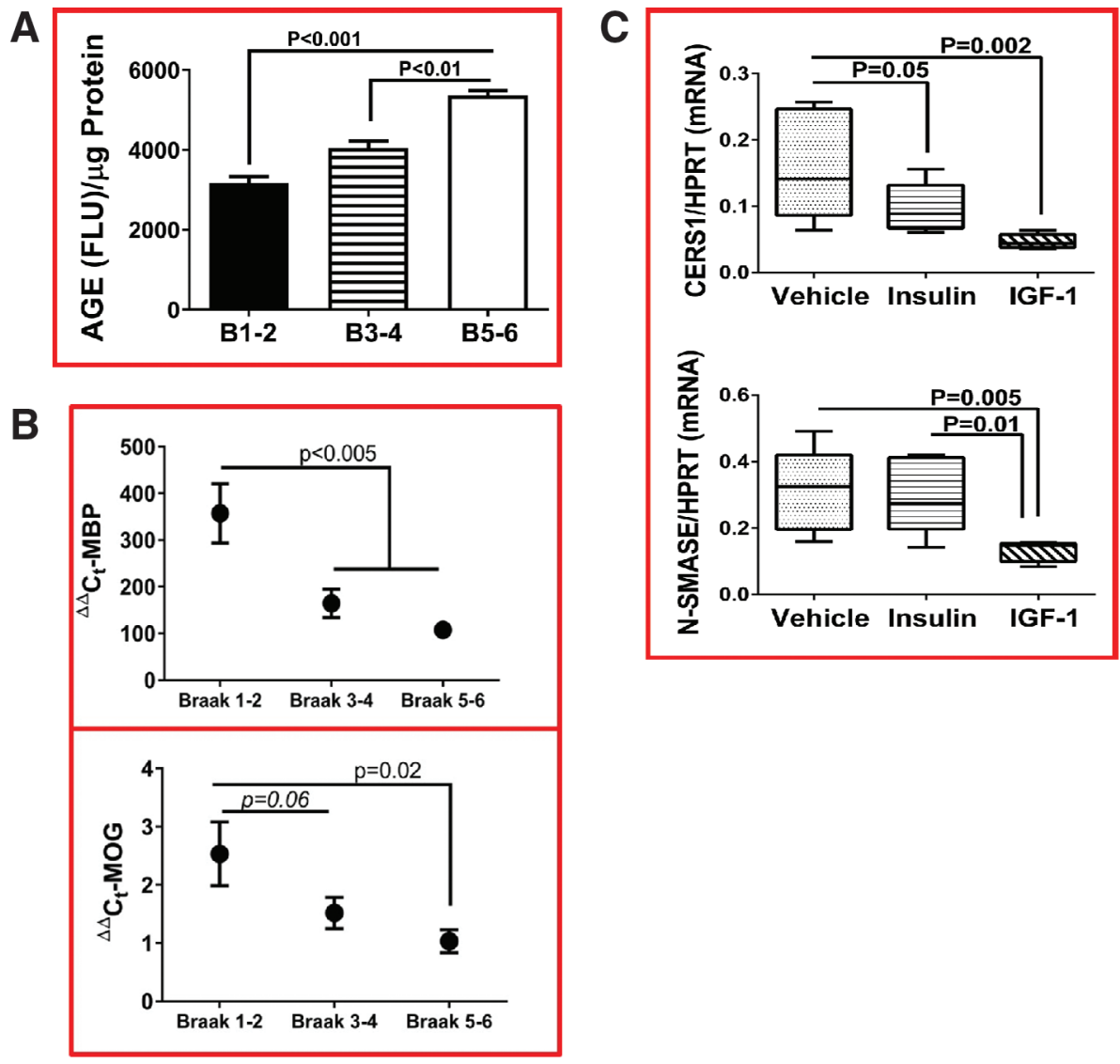

Figure 4 Cellular signaling abnormalities mediating WM degeneration. (A) Advanced glycation end-product (AGE) immunoreactivity was measured in postmortem frontal WM homogenates from humans with normal aging (Braak 0-2; B0-2), moderate AD (B3-4), or severe AD (B5-6) AD using a direct binding ELISA (107). Immunoreactivity was detected with horseradish peroxidase-conjugated secondary antibody and Amplex Red fluorophor. Fluorescence light units (FLU) were measured (Ex $579 \mathrm{~nm} / \mathrm{Em} 595 \mathrm{~nm}$ ) in a Spectromax M5, and results were normalized to protein content. (B) AD WM atrophy and degeneration are associated with reduced expression of mature MAGs. Quantitative RT-PCR was used to measure mRNA levels of MAG 1 and myelin oligodendroglial glycoprotein (MOG). PCR primer pairs were designed with Primer 3 (http://primer3. sourceforge.net/) software. PCR reactions were performed in a Roche Lightcycler 480 System (116). Gene expression was analyzed using the ${ }^{\Delta \Delta} C_{t}$ method with results normalized to hypoxanthine-guanine phosphoribosyl transferase, HPRT. (C) Insulin and IGF-1 suppress expression of genes encoding enzymes that produce ceramides or break down sphingomyelin. Frontal lobe WM slice cultures from an i.c. STZ adult Long Evans rat model of sporadic AD (109) were stimulated for $24 \mathrm{~h}$ with $10 \mathrm{nM}$ insulin, $10 \mathrm{nM}$ IGF-1, or vehicle (control). Graphs depict the mean \pm S.E.M. for each group. Intergroup comparisons were made by one-way ANOVA with the post hoc Tukey's test. Significant P-values and trends are indicated. 
immature myelin-associated genes (116), corresponding with deficits in myelin maturation and striking alterations in WM structure (117). Similar observations have been made in human postmortem brains with different severities of AD and WM atrophy (Figure 4B).

An additional feature of experimental brain insulin resistance with WM atrophy is that oligodendrocyte dysfunction is associated with altered expression of sphingolipid metabolizing enzymes such that ceramide accumulation and sulfatide depletion would be favored (Figure 4C) $(118,119)$. In humans and experimental animals, reductions in brain sulfatide and increases in ceramide correlate with cognitive impairment, oxidative stress, lipid peroxidation, and neuroinflammation $(22-24,120)$. Ceramides inhibit insulin signaling through PI3K-Akt $(25,121)$ and increase oxidative stress, $A \beta$, pTau, and pro-apoptosis activation (122). Furthermore, preliminary studies suggest that insulin and IGF-1 stimulation suppress expression of enzymes that generate ceramides via degradation of sphingomyelin (Figure 4C). Therefore, it is likely that impairments in insulin/ IGF-1 signaling in oligodendrocytes are important in the pathogenesis of WM atrophy and degeneration and mediate disease progression in $\mathrm{AD}$.

\section{Proposed role of APOE- $\varepsilon 4$}

Apolipoprotein $\mathrm{E}$ is the major lipid transport protein in the CNS. This $34 \mathrm{kDa}$ protein has three major isoforms (APOE- $\varepsilon 2$, APOE- $\varepsilon 3$, and APOE- $\varepsilon 4$ ) that differ by single amino acid substitutions at residues 112 and 158 (123). The $\varepsilon 4$ allele is the strongest genetic risk factor for late-onset sporadic AD (124-127) in that carriers account for over 50\% of all AD cases (128); however, the APOE- 44 risk assessments vary across different countries and ethnicities (129). AD risk is increased by three- or fourfold among APOE- $\varepsilon 4$ carriers, and 15 -fold in APOE- $\varepsilon 4$ homozygotes. APOE- $\varepsilon 4$ confers increased risk for $\mathrm{AD}$ by reducing brain glucose metabolism in the preclinical stages of disease (130), and ultimately impairing signal transduction through the insulin receptor, reducing $A \beta$ clearance, and increasing $A \beta$ aggregation (131). APOE- $\varepsilon 4$ may also have a role in mediating AD-associated WM degeneration via insulin resistance (131) and attendant microvascular endothelial cell and oligodendrocyte dysfunction.

\section{Insulin/IGF signaling impairments and glial-vascular WM pathologies in AD}

Our overarching hypothesis is that in $\mathrm{AD}$, WM degeneration is mediated by impairments in insulin and IGF signaling that cast a wide net of pathophysiological responses including oxidative stress, inflammation, and dysregulated glucose and lipid metabolism (Figure 5). In WM, the targets of degeneration are oligodendrocytes and microvessels. Reduced signaling through insulin/IGF receptors, IRS and downstream Akt pathways compromises oligodendrocyte survival, myelin maintenance and integrity, and sphingolipid homeostasis, favoring sulfatide depletion and ceramide accumulation. Ceramide-mediated neurotoxicity, inflammation, oxidative stress, lipid peroxidation, and further impairment of insulin signaling reinforce the cascade of WM degeneration. 


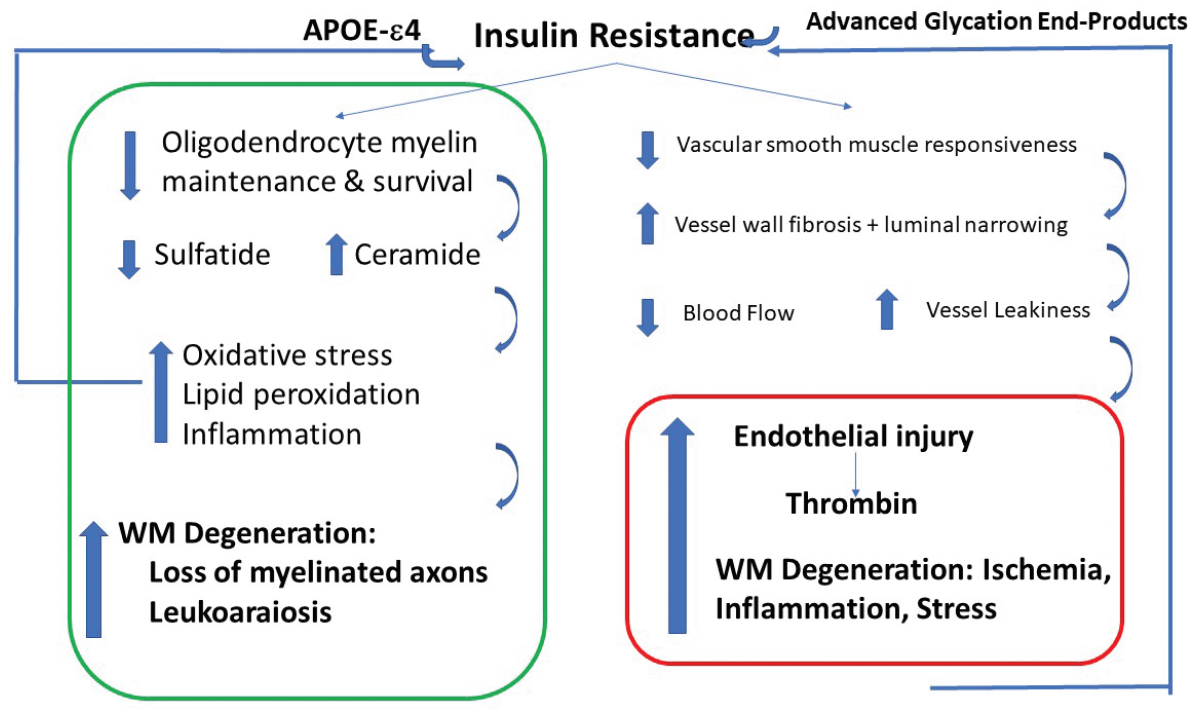

Figure 5 Hypothesis: White matter degeneration in AD is mediated by insulin and IGF resistances that target oligodendrocytes and microvessels. Reduced myelin and vascular integrity promote neuroinflammation, stress, and ischemic injury. APOE- $\varepsilon 4$ genotype, obesogenic diets, and poor lifestyle choices have cofactor roles in mediating WM degeneration due to exacerbation of insulin resistance.

Microvascular disease is also driven by insulin deficient and resistant states such as in types 1 and 2 diabetes mellitus. Initially, microvascular disease is mediated by combined effects of hyperglycemia, increased levels of AGE (Figure 4A), up-regulation of receptors for AGE (RAGE), and reduced responsiveness to NOS/NO $(67,132)$. Therefore, insulin and IGF resistances negatively impact microvascular structural integrity, vaso-responsiveness, and endothelial function. In later stages, microvascular disease is associated with the replacement of smooth muscle by collagen (sclerosis) leading to degenerative mural fibrosis and luminal narrowing, restricted blood flow, reduced vessel wall integrity marked by increased leakiness, and endothelial damage with attendant up-regulation and release of thrombin. Thrombin activation drives inflammation (cytokines), oxidative stress, microvascular occlusions. Microvascular occlusions cause ischemia which can injure oligodendrocytes, myelin, axons, and vessels. Also, vessel wall leakiness exposes perivascular tissue to toxins from the peripheral circulation. Late and probably permanent microvascular-associated WM pathologies in AD include leukoaraiosis with loss of myelin and degeneration of axons, microinfarcts, perivascular tissue attrition, and vasculopenia (vessels can be destroyed by ischemic necrosis). Finally, microvascular disease can drive WM degeneration by worsening insulin resistance, oxidative stress, and inflammation.

Inflammation and oxidative stress are recognized mediators of neurodegeneration in $\mathrm{AD}(26,39,133)$. Potential sources of stress and inflammation include increased levels of AGE and RAGE expression (107, 108, 132, 134-137), impaired insulin/IGF signaling through Akt pathways, lipid peroxidation linked to myelin 
breakdown, and ceramide accumulation. Neuroinflammation in AD is associated with increased pro-inflammatory cytokine expression in astrocytes and microglia $(133,138,139)$. Although TNF- $\alpha$, IFN- $\gamma$ and IL- $1 \beta$ are key players, preliminary data suggest that neuroinflammatory responses are broader and include activation of proinflammatory and inhibition of neuroprotective cytokines/chemokines $(17,140)$.

\section{CONCLUSION}

Combined effects of oligodendrocyte and microvascular dysfunction interact to cause WM degeneration, including leukoaraiosis in AD. Insulin resistance exacerbation by APOE- $\varepsilon 4$ may accelerate AD-associated WM molecular, biochemical, and structural pathologies linked to impaired function of oligodendrocytes and microvascular endothelial cells. Therefore, WM degeneration and cognitive impairment may be preventable or reversible by lifestyle measures that restore insulin responsiveness in the CNS.

Acknowledgments: This research was supported by grants AA11431, AA024092, and HD057100 from the National Institutes of Health.

Conflict of interest: The authors declare no potential conflicts of interest with respect to research, authorship, and/or publication of this chapter.

Copyright and Permission Statement: To the best of our knowledge, the materials included in this chapter do not violate copyright laws. All original sources have been appropriately acknowledged and/or referenced. Where relevant, appropriate permissions have been obtained from the original copyright holder(s).

\section{REFERENCES}

1. Alzheimer's Association. New Alzheimer's Association report reveals sharp increases in Alzheimer's prevalence, deaths, costs of care. May, 2018. Available from: https://www.alz.org/news/2018/ new_alzheimer_s_association_report_reveals_sharp_i

2. Etiene D, Kraft J, Ganju N, Gomez-Isla T, Gemelli B, Hyman BT, et al. Cerebrovascular pathology contributes to the heterogeneity of Alzheimer's disease. J Alzheimers Dis. 1998;1(2):119-34. http:// dx.doi.org/10.3233/JAD-1998-1205

3. Scheltens P, Blennow K, Breteler MM, de Strooper B, Frisoni GB, Salloway S, et al. Alzheimer's disease. Lancet. 2016;388(10043):505-17. http://dx.doi.org/10.1016/S0140-6736(15)01124-1

4. Brun A, Englund E. A white matter disorder in dementia of the Alzheimer type: A pathoanatomical study. Ann Neurol. 1986;19(3):253-62. http://dx. doi.org/10.1002/ana.410190306

5. Brun A, Englund E. Brain changes in dementia of Alzheimer's type relevant to new imaging diagnostic methods. Prog Neuropsychopharmacol Biol Psychiatry. 1986;10(3-5):297-308. http://dx.doi. org/10.1016/0278-5846(86)90009-6

6. de la Monte SM. Quantitation of cerebral atrophy in preclinical and end-stage Alzheimer's disease. Ann Neurol. 1989;25(5):450-9. http://dx.doi.org/10.1002/ana.410250506

7. Scheltens P. Imaging in Alzheimer's disease. Dialogues Clin Neurosci. 2009;11(2):191-9.

8. Scheltens P, Barkhof F, Leys D, Wolters EC, Ravid R, Kamphorst W. Histopathologic correlates of white matter changes on MRI in Alzheimer's disease and normal aging. Neurology. 1995;45(5):883-8. http://dx.doi.org/10.1212/WNL.45.5.883 
9. Scheltens PH. Structural neuroimaging of Alzheimer's disease and other dementias. Aging (Milano). 2001;13(3):203-9. http://dx.doi.org/10.1007/BF03351478

10. Brickman AM, Honig LS, Scarmeas N, Tatarina O, Sanders L, Albert MS, et al. Measuring cerebral atrophy and white matter hyperintensity burden to predict the rate of cognitive decline in Alzheimer disease. Arch Neurol. 2008;65(9):1202-8. http://dx.doi.org/10.1001/archneur.65.9.1202

11. Burns JM, Church JA, Johnson DK, Xiong C, Marcus D, Fotenos AF, et al. White matter lesions are prevalent but differentially related with cognition in aging and early Alzheimer disease. Arch Neurol. 2005;62(12):1870-6. http://dx.doi.org/10.1001/archneur.62.12.1870

12. Brilliant M, Hughes L, Anderson D, Ghobrial M, Elble R. Rarefied white matter in patients with Alzheimer disease. Alzheimer Dis Assoc Disord. 1995;9(1):39-46. http://dx.doi. org/10.1097/00002093-199505000-00008

13. Englund E. Neuropathology of white matter changes in Alzheimer's disease and vascular dementia. Dement Geriatr Cogn Disord. 1998;9(Suppl 1):6-12. http://dx.doi.org/10.1159/000051183

14. Sjobeck M, Englund E. Glial levels determine severity of white matter disease in Alzheimer's disease: A neuropathological study of glial changes. Neuropathol Appl Neurobiol. 2003;29(2):159-69. http:// dx.doi.org/10.1046/j.1365-2990.2003.00456.x

15. Sjobeck M, Haglund M, Englund E. Decreasing myelin density reflected increasing white matter pathology in Alzheimer's disease - A neuropathological study. Int J Geriatr Psychiatry. 2005;20(10):919-26. http://dx.doi.org/10.1002/gps.1384

16. Hovens I, Nyakas C, Schoemaker R. A novel method for evaluating microglial activation using ionized calcium-binding adaptor protein-1 staining: Cell body to cell size ratio. Neuroimmunol Neuroinflamm. 2014;1(2):82-8. http://dx.doi.org/10.4103/2347-8659.139719

17. de la Monte SM, Daiello LA, Hapel AJ, Tong M, Ott BR. Altered serum and cerebrospinal fluid inflammatory cascades in mild cognitive impairment and Alzheimer's disease. J Neuroinflam Neurodegen. 2017;1(1):100004, 1-24.

18. Flores-Obando RE, Freidin MM, Abrams CK. Rapid and specific immunomagnetic isolation of mouse primary oligodendrocytes. J Vis Exp. 2018;135(135):357543. http://dx.doi.org/10.3791/57543

19. Tong M, Leao R, Vimbela GV, Yalcin EB, Kay J, Krotow A, et al. Altered temporal lobe white matter lipid ion profiles in an experimental model of sporadic Alzheimer's disease. Mol Cell Neurosci. 2017;82:23-34. http://dx.doi.org/10.1016/j.mcn.2017.04.010

20. Han X. Multi-dimensional mass spectrometry-based shotgun lipidomics and the altered lipids at the mild cognitive impairment stage of Alzheimer's disease. Biochim Biophys Acta. 2010;1801(8): 774-83. http://dx.doi.org/10.1016/j.bbalip.2010.01.010

21. Quarles RH, Macklin WB, Morell P. Myelin formation, structure and biochemistry. 6th ed. Philadelphia, PA: Elsevier; 2006.

22. Han X. Lipid alterations in the earliest clinically recognizable stage of Alzheimer's disease: Implication of the role of lipids in the pathogenesis of Alzheimer's disease. Curr Alzheimer Res. 2005;2(1):65-77. http://dx.doi.org/10.2174/1567205052772786

23. Han X, D MH, McKeel DW, Jr., Kelley J, Morris JC. Substantial sulfatide deficiency and ceramide elevation in very early Alzheimer's disease: Potential role in disease pathogenesis. J Neurochem. 2002;82(4):809-18. http://dx.doi.org/10.1046/j.1471-4159.2002.00997.x

24. Irizarry MC. A turn of the sulfatide in Alzheimer's disease. Ann Neurol. 2003;54(1):7-8. http://dx.doi. org/10.1002/ana.10642

25. Czubowicz K, Strosznajder R. Ceramide in the molecular mechanisms of neuronal cell death. The role of sphingosine-1-phosphate. Mol Neurobiol. 2014;50(1):26-37. http://dx.doi.org/10.1007/ s12035-013-8606-4

26. de la Monte SM. Triangulated mal-signaling in Alzheimer's disease: Roles of neurotoxic ceramides, ER stress, and insulin resistance reviewed. J Alzheimers Dis. 2012;30(Suppl 2):S231-49. http://dx.doi. org/10.3233/JAD-2012-111727

27. de la Monte SM, Re E, Longato L, Tong M. Dysfunctional pro-ceramide, ER stress, and insulin/IGF signaling networks with progression of Alzheimer's disease. J Alzheimers Dis. 2012;30(Suppl 2): S217-29. http://dx.doi.org/10.3233/JAD-2012-111728

28. de la Monte SM, Tong M, Nguyen V, Setshedi M, Longato L, Wands JR. Ceramide-mediated insulin resistance and impairment of cognitive-motor functions. J Alzheimers Dis. 2010;21(3):967-84. http://dx.doi.org/10.3233/JAD-2010-091726 
29. Vos JP, Lopes-Cardozo M, Gadella BM. Metabolic and functional aspects of sulfogalactolipids. Biochim Biophys Acta. 1994;1211(2):125-49. http://dx.doi.org/10.1016/0005-2760(94)90262-3

30. Takahashi T, Suzuki T. Role of sulfatide in normal and pathological cells and tissues. J Lipid Res. 2012;53(8):1437-50. http://dx.doi.org/10.1194/jlr.R026682

31. Eckhardt M. The role and metabolism of sulfatide in the nervous system. Mol Neurobiol. 2008; 37(2-3):93-103. http://dx.doi.org/10.1007/s12035-008-8022-3

32. Kolesnick RN, Kronke M. Regulation of ceramide production and apoptosis. Ann Rev Physiol. 1998;60:643-65. http://dx.doi.org/10.1146/annurev.physiol.60.1.643

33. Campagnoni AT, Macklin WB. Cellular and molecular aspects of myelin protein gene expression. Mol Neurobiol. 1988;2(1):41-89. http://dx.doi.org/10.1007/BF02935632

34. Nave KA, Milner RJ. Proteolipid proteins: Structure and genetic expression in normal and myelindeficient mutant mice. Crit Rev Neurobiol. 1989;5(1):65-91.

35. Gordon MN, Kumar S, Espinosa de los Monteros A, Scully S, Zhang MS, Huber J, et al. Developmental regulation of myelin-associated genes in the normal and the myelin deficient mutant rat. Adv Exp Med Biol. 1990;265:11-22. http://dx.doi.org/10.1007/978-1-4757-5876-4_2

36. Collarini EJ, Pringle N, Mudhar H, Stevens G, Kuhn R, Monuki ES, et al. Growth factors and transcription factors in oligodendrocyte development. J Cell Sci Suppl. 1991;15:117-23. http://dx.doi. org/10.1242/jcs.1991.Supplement_15.16

37. Wallin A, Nordlund A, Jonsson M, Blennow K, Zetterberg H, Ohrfelt A, et al. Alzheimer's disease Subcortical vascular disease spectrum in a hospital-based setting: Overview of results from the Gothenburg MCI and dementia studies. J Cereb Blood Flow Metab. 2016;36(1):95-113. http:// dx.doi.org/10.1038/jcbfm.2015.148

38. de la Monte SM. Contributions of brain insulin resistance and deficiency in amyloidrelated neurodegeneration in Alzheimer's disease. Drugs. 2012;72(1):49-66. http://dx.doi. org/10.2165/11597760-000000000-00000

39. de la Monte SM. Insulin resistance and neurodegeneration: Progress towards the development of new therapeutics for Alzheimer's disease. Drugs. 2017;77(1):47-65. http://dx.doi.org/10.1007/ s40265-016-0674-0

40. de la Monte SM, Wands JR. Review of insulin and insulin-like growth factor expression, signaling, and malfunction in the central nervous system: Relevance to Alzheimer's disease. J Alzheimers Dis. 2005;7(1):45-61. http://dx.doi.org/10.3233/JAD-2005-7106

41. Rivera EJ, Goldin A, Fulmer N, Tavares R, Wands JR, de la Monte SM. Insulin and insulin-like growth factor expression and function deteriorate with progression of Alzheimer's disease: Link to brain reductions in acetylcholine. J Alzheimers Dis. 2005;8(3):247-68. http://dx.doi.org/10.3233/ JAD-2005-8304

42. Steen E, Terry BM, Rivera EJ, Cannon JL, Neely TR, Tavares R, et al. Impaired insulin and insulin-like growth factor expression and signaling mechanisms in Alzheimer's disease--is this type 3 diabetes? J Alzheimers Dis. 2005;7(1):63-80. http://dx.doi.org/10.3233/JAD-2005-7107

43. Chesik D, De Keyser J, Wilczak N. Insulin-like growth factor system regulates oligodendroglial cell behavior: Therapeutic potential in CNS. J Mol Neurosci. 2008;35(1):81-90. http://dx.doi. org/10.1007/s12031-008-9041-2

44. Freude S, Leeser U, Muller M, Hettich MM, Udelhoven M, Schilbach K, et al. IRS-2 branch of IGF-1 receptor signaling is essential for appropriate timing of myelination. J Neurochem. 2008;107(4): 907-17. http://dx.doi.org/10.1111/j.1471-4159.2008.05631.x

45. Gong X, Xie Z, Zuo H. Invivo insulin deficiency as a potential etiology for demyelinating disease. Med Hypotheses. 2008;71(3):399-403. http://dx.doi.org/10.1016/j.mehy.2008.04.006

46. Barres BA, Schmid R, Sendnter M, Raff MC. Multiple extracellular signals are required for long-term oligodendrocyte survival. Development (Cambridge, England). 1993;118(1):283-95.

47. de la Monte SM, Tong M, Lester-Coll N, Plater M Jr., Wands JR. Therapeutic rescue of neurodegeneration in experimental type 3 diabetes: Relevance to Alzheimer's disease. J Alzheimers Dis. 2006;10(1):89-109. http://dx.doi.org/10.3233/JAD-2006-10113

48. Lester-Coll N, Rivera EJ, Soscia SJ, Doiron K, Wands JR, de la Monte SM. Intracerebral streptozotocin model of type 3 diabetes: Relevance to sporadic Alzheimer's disease. J Alzheimers Dis. 2006;9(1): 13-33. http://dx.doi.org/10.3233/JAD-2006-9102 
49. de la Monte SM, Tong M, Schiano I, Didsbury J. Improved brain insulin/IGF signaling and reduced neuroinflammation with T3D-959 in an experimental model of sporadic Alzheimer's disease. J Alzheimers Dis. 2017;55(2):849-64. http://dx.doi.org/10.3233/JAD-160656

50. de la Monte SM. Metabolic derangements mediate cognitive impairment and Alzheimer's disease: Role of peripheral insulin-resistance diseases. Panminerva Med. 2012;54(3):171-8.

51. de la Monte SM, Longato L, Tong M, Wands JR. Insulin resistance and neurodegeneration: Roles of obesity, type 2 diabetes mellitus and non-alcoholic steatohepatitis. Curr Opin Investig Drugs. 2009;10(10):1049-60.

52. de la Monte SM, Tong M. Brain metabolic dysfunction at the core of Alzheimer's disease. Biochem Pharmacol. 2014;88(4):548-59. http://dx.doi.org/10.1016/j.bcp.2013.12.012

53. Bordner KA, George ED, Carlyle BC, Duque A, Kitchen RR, Lam TT, et al. Functional genomic and proteomic analysis reveals disruption of myelin-related genes and translation in a mouse model of early life neglect. Front Psychiatry. 2011;2:18. http://dx.doi.org/10.3389/ fpsyt.2011.00018

54. Back SA. White matter injury in the preterm infant: Pathology and mechanisms. Acta Neuropathol. 2017;134(3):331-49. http://dx.doi.org/10.1007/s00401-017-1718-6

55. Nicklay JJ, Harris GA, Schey KL, Caprioli RM. MALDI imaging and in situ identification of integral membrane proteins from rat brain tissue sections. Anal Chem. 2013;85(15):7191-6. http://dx.doi. org/10.102l/ac400902h

56. Groseclose MR, Andersson M, Hardesty WM, Caprioli RM. Identification of proteins directly from tissue: In situ tryptic digestions coupled with imaging mass spectrometry. J Mass Spectrom. 2007;42(2):254-62. http://dx.doi.org/10.1002/jms.1177

57. Cheng H, Xu J, McKeel DW Jr., Han X. Specificity and potential mechanism of sulfatide deficiency in Alzheimer's disease: An electrospray ionization mass spectrometric study. Cell Mol Biol (Noisy-legrand). 2003;49(5):809-18.

58. de la Torre JC. Cerebral hypoperfusion, capillary degeneration, and development of Alzheimer disease. Alzheimer Dis Assoc Disord. 2000;14(Suppl 1):S72-81. http://dx.doi.org/10.1097/00002093200000001-00012

59. de la Torre JC, Mussivand T. Can disturbed brain microcirculation cause Alzheimer's disease? Neurol Res. 1993;15(3):146-53. http://dx.doi.org/10.1080/01616412.1993.11740127

60. Toledo JB, Arnold SE, Raible K, Brettschneider J, Xie SX, Grossman M, et al. Contribution of cerebrovascular disease in autopsy confirmed neurodegenerative disease cases in the National Alzheimer's Coordinating Centre. Brain. 2013;136(Pt 9):2697-706. http://dx.doi.org/10.1093/ brain/awt 188

61. Joachim CL, Selkoe DJ. The seminal role of beta-amyloid in the pathogenesis of Alzheimer disease. Alzheimer Dis Assoc Disord. 1992;6(1):7-34. http://dx.doi.org/10.1097/00002093-19920 5000-00003

62. Vinters HV. Emerging concepts in Alzheimer's disease. Annu Rev Pathol. 2015;10:291-319. http:// dx.doi.org/10.1146/annurev-pathol-020712-163927

63. Vinters HV, Wang ZZ, Secor DL. Brain parenchymal and microvascular amyloid in Alzheimer's disease. Brain Pathol. 1996;6(2):179-95. http://dx.doi.org/10.1111/j.1750-3639.1996.tb00799.x

64. Scheibel AB, Duong TH, Jacobs R. Alzheimer's disease as a capillary dementia. Ann Med. 1989;21(2):103-7. http://dx.doi.org/10.3109/07853898909149194

65. Buee L, Hof PR, Delacourte A. Brain microvascular changes in Alzheimer's disease and other dementias. Ann N Y Acad Sci. 1997;826:7-24. http://dx.doi.org/10.1111/j.1749-6632.1997.tb48457.x

66. Farkas E, De Jong GI, Apro E, De Vos RA, Steur EN, Luiten PG. Similar ultrastructural breakdown of cerebrocortical capillaries in Alzheimer's disease, Parkinson's disease, and experimental hypertension. What is the functional link? Ann N Y Acad Sci. 2000;903:72-82. http://dx.doi. org/10.1111/j.1749-6632.2000.tb06352.x

67. Perlmutter LS, Chui HC. Microangiopathy, the vascular basement membrane and Alzheimer's disease: A review. Brain Res Bull. 1990;24(5):677-86. http://dx.doi.org/10.1016/0361-9230(90)90007-M

68. Chalmers K, Wilcock G, Love S. Contributors to white matter damage in the frontal lobe in Alzheimer's disease. Neuropathol Appl Neurobiol. 2005;31(6):623-31. http://dx.doi.org/10.1111/j. 1365-2990.2005.00678.x 
69. Jellinger KA. The pathology of ischemic-vascular dementia: An update. J Neurol Sci. 2002;203204:153-7. http://dx.doi.org/10.1016/S0022-510X(02)00282-4

70. Thal LJ. Therapeutics and mild cognitive impairment: Current status and future directions. Alzheimer Dis Assoc Disord. 2003;17(Suppl2):S69-71. http://dx.doi.org/10.1097/00002093-200304002-00012

71. Verny M, Duyckaerts C, Pierot L, Hauw JJ. Leuko-araiosis. Dev Neurosci. 1991;13(4-5):245-50. http://dx.doi.org/10.1159/000112168

72. Neltner JH, Abner EL, Baker S, Schmitt FA, Kryscio RJ, Jicha GA, et al. Arteriolosclerosis that affects multiple brain regions is linked to hippocampal sclerosis of ageing. Brain. 2014;137(Pt 1):255-67. http://dx.doi.org/10.1093/brain/awt318

73. Kalaria RN, Akinyemi R, Ihara M. Does vascular pathology contribute to Alzheimer changes? J Neurol Sci. 2012;322(1-2):141-7. http://dx.doi.org/10.1016/j.jns.2012.07.032

74. Ferrer I, Bella R, Serrano MT, Marti E, Guionnet N. Arteriolosclerotic leucoencephalopathy in the elderly and its relation to white matter lesions in Binswanger's disease, multi-infarct encephalopathy and Alzheimer's disease. J Neurol Sci. 1990;98(1):37-50. http://dx.doi.org/10.1016/0022-510X(90)90180-U

75. Dorheim MA, Tracey WR, Pollock JS, Grammas P. Nitric oxide synthase activity is elevated in brain microvessels in Alzheimer's disease. Biochem Biophys Res Commun. 1994;205(1):659-65. http:// dx.doi.org/10.1006/bbrc.1994.2716

76. Wang S, Qaisar U, Yin X, Grammas P. Gene expression profiling in Alzheimer's disease brain microvessels. J Alzheimers Dis. 2012;31(1):193-205. http://dx.doi.org/10.3233/JAD-2012-120454

77. de la Monte SM, Sohn YK, Etienne D, Kraft J, Wands JR. Role of aberrant nitric oxide synthase-3 expression in cerebrovascular degeneration and vascular-mediated injury in Alzheimer's disease. Ann N Y Acad Sci. 2000;903:61-71. http://dx.doi.org/10.1111/j.1749-6632.2000.tb06351.x

78. Grammas P. A damaged microcirculation contributes to neuronal cell death in Alzheimer's disease. Neurobiol Aging. 2000;21(2):199-205. http://dx.doi.org/10.1016/S0197-4580(00)00102-0

79. Yin X, Wright J, Wall T, Grammas P. Brain endothelial cells synthesize neurotoxic thrombin in Alzheimer's disease. Am J Pathol. 2010;176(4):1600-6. http://dx.doi.org/10.2353/ajpath.2010.090406

80. Grammas P. Neurovascular dysfunction, inflammation and endothelial activation: Implications for the pathogenesis of Alzheimer's disease. J Neuroinflamm. 2011;8:26. http://dx.doi.org/10.1186/ 1742-2094-8-26

81. Grammas P, Yamada M, Zlokovic B. The cerebromicrovasculature: A key player in the pathogenesis of Alzheimer's disease. J Alzheimers Dis. 2002;4(3):217-23. http://dx.doi.org/10.3233/JAD-2002-4311

82. van Hinsbergh VW. Endothelium - Role in regulation of coagulation and inflammation. Semin Immunopathol. 2012;34(1):93-106. http://dx.doi.org/10.1007/s00281-011-0285-5

83. Bartha K, Domotor E, Lanza F, Adam-Vizi V, Machovich R. Identification of thrombin receptors in rat brain capillary endothelial cells. J Cereb Blood Flow Metab. 2000;20(1):175-82. http://dx.doi. org/10.1097/00004647-200001000-00022

84. Yin M, Chen Z, Ouyang Y, Zhang H, Wan Z, Wang H, et al. Thrombin-induced, TNFR-dependent miR-181c downregulation promotes MLLl and NF-kappaB target gene expression in human microglia. J Neuroinflammation. 2017;14(1):132. http://dx.doi.org/10.1186/s12974-017-0887-5

85. Choi MS, Kim YE, Lee WJ, Choi JW, Park GH, Kim SD, et al. Activation of protease-activated receptorl mediates induction of matrix metalloproteinase- 9 by thrombin in rat primary astrocytes. Brain Res Bull. 2008;76(4):368-75. http://dx.doi.org/10.1016/j.brainresbull.2008.02.031

86. Hayakawa K, Seo JH, Pham LD, Miyamoto N, Som AT, Guo S, et al. Cerebral endothelial derived vascular endothelial growth factor promotes the migration but not the proliferation of oligodendrocyte precursor cells in vitro. Neurosci Lett. 2012;513(1):42-6. http://dx.doi.org/10.1016/j. neulet.2012.02.004

87. Kurachi M, Mikuni M, Ishizaki Y. Extracellular vesicles from vascular endothelial cells promote survival, proliferation and motility of oligodendrocyte precursor cells. PLoS One. 2016;11(7):e0159158. http://dx.doi.org/10.1371/journal.pone.0159158

88. Rajani RM, Quick S, Ruigrok SR, Graham D, Harris SE, Verhaaren BFJ, et al. Reversal of endothelial dysfunction reduces white matter vulnerability in cerebral small vessel disease in rats. Sci Transl Med. 2018;10:448. http://dx.doi.org/10.1126/scitranslmed.aam9507

89. Sanchez A, Tripathy D, Luo J, Yin X, Martinez J, Grammas P. Neurovascular unit and the effects of dosage in VEGF toxicity: Role for oxidative stress and thrombin. J Alzheimers Dis. 2013;34(1):281-91. http://dx.doi.org/10.3233/JAD-121636 
90. Grammas P, Samany PG, Thirumangalakudi L. Thrombin and inflammatory proteins are elevated in Alzheimer's disease microvessels: Implications for disease pathogenesis. J Alzheimers Dis. 2006;9(1):51-8. http://dx.doi.org/10.3233/JAD-2006-9105

91. Luo J, Grammas P. Endothelin-1 is elevated in Alzheimer's disease brain microvessels and is neuroprotective. J Alzheimers Dis. 2010;21(3):887-96. http://dx.doi.org/10.3233/JAD-2010-091486

92. Grammas P, Martinez JM. Targeting thrombin: An inflammatory neurotoxin in Alzheimer's disease. J Alzheimers Dis. 2014;42(Suppl 4):S537-44. http://dx.doi.org/10.3233/JAD-141557

93. Yoon H, Radulovic M, Drucker KL, Wu J, Scarisbrick IA. The thrombin receptor is a critical extracellular switch controlling myelination. Glia. 2015;63(5):846-59. http://dx.doi.org/10.1002/glia.22788

94. Undas A, Wiek I, Stepien E, Zmudka K, Tracz W. Hyperglycemia is associated with enhanced thrombin formation, platelet activation, and fibrin clot resistance to lysis in patients with acute coronary syndrome. Diabetes Care. 2008;31(8):1590-5. http://dx.doi.org/10.2337/dc08-0282

95. Ceriello A, Giacomello R, Stel G, Motz E, Taboga C, Tonutti L, et al. Hyperglycemia-induced thrombin formation in diabetes. The possible role of oxidative stress. Diabetes. 1995;44(8):924-8. http:// dx.doi.org/10.2337/diab.44.8.924

96. Liu Y, Chen XL, Wang L, Martins-Green M. Insulin antagonizes thrombin-induced microvessel leakage. J Vasc Res. 2017;54(3):143-55. http://dx.doi.org/10.1159/000470844

97. de Leon MJ, George AE, Ferris SH, Rosenbloom S, Christman DR, Gentes CI, et al. Regional correlation of PET and CT in senile dementia of the Alzheimer type. AJNR Am J Neuroradiol. 1983;4(3):553-6.

98. Faulstich ME. Brain imaging in dementia of the Alzheimer type. Int J Neurosci. 1991;57(1-2):39-49. http://dx.doi.org/10.3109/00207459109150345

99. Waldron AM, Wintmolders C, Bottelbergs A, Kelley JB, Schmidt ME, Stroobants S, et al. In vivo molecular neuroimaging of glucose utilization and its association with fibrillar amyloid-beta load in aged APPPS1-21 mice. Alzheimers Res Ther. 2015;7(1):76. http://dx.doi.org/10.1186/s13195-015-0158-6

100. Wurtman R. Biomarkers in the diagnosis and management of Alzheimer's disease. Metabolism. 2015;64(3 Suppl 1):S47-50. http://dx.doi.org/10.1016/j.metabol.2014.10.034

101. Daulatzai MA. Quintessential risk factors: Their role in promoting cognitive dysfunction and Alzheimer's disease. Neurochem Res. 2012;37(12):2627-58. http://dx.doi.org/10.1007/s11064-012-0854-6

102. Daulatzai MA. Cerebral hypoperfusion and glucose hypometabolism: Key pathophysiological modulators promote neurodegeneration, cognitive impairment, and Alzheimer's disease. J Neurosci Res. 2017;95(4):943-72. http://dx.doi.org/10.1002/jnr.23777

103. Schaffer C, Sarad N, DeCrumpe A, Goswami D, Herrmann S, Morales J, et al. Biomarkers in the diagnosis and prognosis of Alzheimer's disease. J Lab Autom. 2015;20(5):589-600. http://dx.doi. org/10.1177/2211068214559979

104. de la Monte SM, Tong M, Bowling N, Moskal P. si-RNA inhibition of brain insulin or insulin-like growth factor receptors causes developmental cerebellar abnormalities: Relevance to fetal alcohol spectrum disorder. Mol Brain. 2011;4:13. http://dx.doi.org/10.1186/1756-6606-4-13

105. de la Monte SM, Wands JR. Alzheimer's disease is type 3 diabetes-evidence reviewed. J Diabetes Sci Technol. 2008;2(6):1101-13. http://dx.doi.org/10.1177/193229680800200619

106. Talbot K, Wang HY, Kazi H, Han LY, Bakshi KP, Stucky A, et al. Demonstrated brain insulin resistance in Alzheimer's disease patients is associated with IGF-1 resistance, IRS-1 dysregulation, and cognitive decline. J Clin Invest. 2012;122(4):1316-38. http://dx.doi.org/10.1172/JC159903

107. Lee S, Tong M, Hang S, Deochand C, de la Monte S. CSF and brain indices of insulin resistance, oxidative stress and neuro-inflammation in early versus late Alzheimer's disease. J Alzheimers Dis Parkinsonism. 2013;3:128.

108. Shuvaev VV, Laffont I, Serot JM, Fujii J, Taniguchi N, Siest G. Increased protein glycation in cerebrospinal fluid of Alzheimer's disease. Neurobiol Aging. 2001;22(3):397-402. http://dx.doi.org/10.1016/ S0197-4580(00)00253-0

109. Tong M, Deochand C, Didsbury J, de la Monte SM. T3D-959: A multi-faceted disease remedial drug candidate for the treatment of Alzheimer's disease. J Alzheimers Dis. 2016;51(1):123-38. http:// dx.doi.org/10.3233/JAD-151013

110. Benedict C, Frey WH, 2nd, Schioth HB, Schultes B, Born J, Hallschmid M. Intranasal insulin as a therapeutic option in the treatment of cognitive impairments. Exp Gerontol. 2011;46(2-3):112-15. http://dx.doi.org/10.1016/j.exger.2010.08.026 
111. de la Monte SM. Intranasal insulin therapy for cognitive impairment and neurodegeneration: Current state of the art. Expert Opin Drug Deliv. 2013;10(12):1699-709. http://dx.doi.org/10.1517/17425247. 2013.856877

112. Kidd PM. Alzheimer's disease, amnestic mild cognitive impairment, and age-associated memory impairment: Current understanding and progress toward integrative prevention. Altern Med Rev. 2008;13(2):85-115.

113. Reger MA, Watson GS, Green PS, Baker LD, Cholerton B, Fishel MA, et al. Intranasal insulin administration dose-dependently modulates verbal memory and plasma amyloid-beta in memory-impaired older adults. J Alzheimers Dis. 2008;13(3):323-31. http://dx.doi.org/10.3233/JAD-2008-13309

114. Reger MA, Watson GS, Green PS, Wilkinson CW, Baker LD, Cholerton B, et al. Intranasal insulin improves cognition and modulates \{beta\}-amyloid in early AD. Neurology. 2008;70(6):440-8. http:// dx.doi.org/10.1212/01.WNL.0000265401.62434.36

115. Tong M, Dominguez C, Didsbury J, de la Monte SM. Targeting Alzheimer's disease neuro-metabolic dysfunction with a small molecule nuclear receptor agonist (T3D-959) reverses disease pathologies. J Alzheimers Dis Parkinsonism. 2016;6(3):238-44. http://dx.doi.org/10.4172/2161-0460.1000238

116. Tong M, Yu R, Silbermann E, Zabala V, Deochand C, de la Monte SM. Differential contributions of alcohol and nicotine-derived nitrosamine ketone (NNK) to white matter pathology in the adolescent rat brain. Alcohol Alcohol. 2015;50(6):680-9. http://dx.doi.org/10.1093/alcalc/agvl02

117. Papp-Peka A, Tong M, Kril JJ, De La Monte SM, Sutherland GT. The differential effects of alcohol and nicotine-specific nitrosamine ketone on white matter ultrastructure. Alcohol Alcohol. 2017;52(2):165-71. http://dx.doi.org/10.1093/alcalc/agw067

118. Lyn-Cook LE, Jr., Lawton M, Tong M, Silbermann E, Longato L, Jiao P, et al. Hepatic ceramide may mediate brain insulin resistance and neurodegeneration in type 2 diabetes and non-alcoholic steatohepatitis. J Alzheimers Dis. 2009;16(4):715-29. http://dx.doi.org/10.3233/JAD-2009-0984

119. Yalcin EB, Nunez K, Tong M, de la Monte SM. Differential sphingolipid and phospholipid profiles in alcohol and nicotine-derived nitrosamine ketone-associated white matter degeneration. Alcohol Clin Exp Res. 2015;39(12):2324-33. http://dx.doi.org/10.1111/acer.12909

120. Gottfries CG, Karlsson I, Svennerholm L. Membrane components separate early-onset Alzheimer's disease from senile dementia of the Alzheimer type. Int Psychogeriatr. 1996;8(3):365-72. http:// dx.doi.org/10.1017/S1041610296002736

121. Zinda MJ, Vlahos CJ, Lai MT. Ceramide induces the dephosphorylation and inhibition of constitutively activated Akt in PTEN negative U87mg cells. Biochem Biophys Res Commun. 2001;280(4):1107-15. http://dx.doi.org/10.1006/bbrc.2000.4248

122. Tong M, de la Monte SM. Mechanisms of ceramide-mediated neurodegeneration. J Alzheimers Dis. 2009;16(4):705-14. http://dx.doi.org/10.3233/JAD-2009-0983

123. Cedazo-Minguez A. Apolipoprotein E and Alzheimer's disease: Molecular mechanisms and therapeutic opportunities. J Cell Mol Med. 2007;11(6):1227-38. http://dx.doi.org/10.1111/j.1582-4934.2007. 00130.x

124. Corder EH, Saunders AM, Strittmatter WJ, Schmechel DE, Gaskell PC, Small GW, et al. Gene dose of apolipoprotein $\mathrm{E}$ type 4 allele and the risk of Alzheimer's disease in late onset families. Science. 1993;261(5123):921-3. http://dx.doi.org/10.1126/science.8346443

125. Myers RH, Schaefer EJ, Wilson PW, D’Agostino R, Ordovas JM, Espino A, et al. Apolipoprotein E epsilon 4 association with dementia in a population-based study: The Framingham study. Neurology. 1996;46(3):673-7. http://dx.doi.org/10.1212/WNL.46.3.673

126. Hofman A, Ott A, Breteler MM, Bots ML, Slooter AJ, van Harskamp F, et al. Atherosclerosis, apolipoprotein E, and prevalence of dementia and Alzheimer's disease in the Rotterdam study. Lancet. 1997;349(9046):151-4. http://dx. doi.org/10.1016/S0140-6736(96)09328-2

127. Strittmatter WJ, Saunders AM, Schmechel D, Pericak-Vance M, Enghild J, Salvesen GS, et al. Apolipoprotein E: High-avidity binding to beta-amyloid and increased frequency of type 4 allele in late-onset familial Alzheimer disease. Proc Natl Acad Sci U S A. 1993;90(5):1977-81. http://dx.doi. org/10.1073/pnas.90.5.1977

128. Liu CC, Liu CC, Kanekiyo T, Xu H, Bu G. Apolipoprotein E and Alzheimer disease: Risk, mechanisms and therapy. Nat Rev Neurol. 2013;9(2):106-18. http://dx.doi.org/10.1038/nrneurol.2012.263 
129. Crean S, Ward A, Mercaldi CJ, Collins JM, Cook MN, Baker NL, et al. Apolipoprotein E epsilon4 prevalence in Alzheimer's disease patients varies across global populations: A systematic literature review and meta-analysis. Dement Geriatr Cogn Disord. 2011;31(1):20-30. http://dx.doi. org/10.1159/000321984

130. Reiman EM, Caselli RJ, Yun LS, Chen K, Bandy D, Minoshima S, et al. Preclinical evidence of Alzheimer's disease in persons homozygous for the epsilon 4 allele for apolipoprotein E. N Engl J Med. 1996;334(12):752-8. http://dx.doi.org/10.1056/NEJM199603213341202

131. Zhao N, Liu CC, Van Ingelgom AJ, Martens YA, Linares C, Knight JA, et al. Apolipoprotein E4 Impairs neuronal insulin signaling by trapping insulin receptor in the endosomes. Neuron. 2017;96(1): 115-29.e5. http://dx.doi.org/10.1016/j.neuron.2017.09.003

132. Yamagishi S, Nakamura N, Suematsu M, Kaseda K, Matsui T. Advanced glycation end products: A molecular target for vascular complications in diabetes. Mol Med. 2015;21(Suppl 1):S32-40. http:// dx.doi.org/10.2119/molmed.2015.00067

133. Agostinho P, Cunha RA, Oliveira C. Neuroinflammation, oxidative stress and the pathogenesis of Alzheimer's disease. Curr Pharm Des. 2010;16(25):2766-78. http://dx.doi.org/10.2174/ 138161210793176572

134. Deane R, Du Yan S, Submamaryan RK, LaRue B, Jovanovic S, Hogg E, et al. RAGE mediates amyloid-beta peptide transport across the blood-brain barrier and accumulation in brain. Nat Med. 2003;9(7):907-13. http://dx.doi.org/10.1038/nm890

135. Donahue JE, Flaherty SL, Johanson CE, Duncan JA, 3rd, Silverberg GD, Miller MC, et al. RAGE, LRP-1, and amyloid-beta protein in Alzheimer's disease. Acta Neuropathol. 2006;112(4):405-15. http://dx.doi.org/10.1007/s00401-006-0115-3

136. Lovestone S, Smith U. Advanced glycation end products, dementia, and diabetes. Proc Natl Acad Sci U S A. 2014;111(13):4743-4. http://dx.doi.org/10.1073/pnas.1402277111

137. Yan SD, Chen X, Fu J, Chen M, Zhu H, Roher A, et al. RAGE and amyloid-beta peptide neurotoxicity in Alzheimer's disease. Nature. 1996;382(6593):685-91. http://dx.doi.org/10.1038/382685a0

138. Piro JR, Benjamin DI, Duerr JM, Pi Y, Gonzales C, Wood KM, et al. A dysregulated endocannabinoid-eicosanoid network supports pathogenesis in a mouse model of Alzheimer's disease. Cell Rep. 2012;1(6):617-23. http://dx.doi.org/10.1016/j.celrep.2012.05.001

139. Singhal G, Jaehne EJ, Corrigan F, Toben C, Baune BT. Inflammasomes in neuroinflammation and changes in brain function: A focused review. Front Neurosci. 2014;8:315. http://dx.doi.org/10.3389/ fnins.2014.00315

140. Liddelow SA, Guttenplan KA, Clarke LE, Bennett FC, Bohlen CJ, Schirmer L, et al. Neurotoxic reactive astrocytes are induced by activated microglia. Nature. 2017;541(7638):481-7. http://dx.doi. org/10.1038/nature21029 